\title{
Germination, seedling performance, and root production after simulated partial seed predation of a threatened Atacama Desert shrub
}

\author{
Andrea P Loayza ${ }^{1,2^{*}}$, Paloma R Gachon ${ }^{1}$, Patricio García-Guzmán ${ }^{1,2,3}$, Danny E Carvajal11,2,3 \\ and Francisco A Squeo ${ }^{1,3,4}$
}

\begin{abstract}
Background: Seed loss to predators is a common phenomenon across plant communities and an important determinant of plant recruitment. Although seed predators commonly destroy the entire seed, partial seed consumption has been reported for many species; however, the degree to which seed mass loss affects germination dynamics and survival of new individuals has been poorly documented. We simulated seed damage in natural conditions to examine how different levels of cotyledonary reserve removal affect germination dynamics and seedling performance of Myrcianthes coquimbensis (Myrtaceae), a threatened Atacama Desert shrub. The experiment combined two levels of seed maturity with three levels of seed mass loss.

Results: Removal of the cotyledon reserves and seed maturity negatively affected the odds and the temporality of seedling emergence; nonetheless, seedlings were able to emerge from seed fragments, of either mature or immature seeds, that lost up to $75 \%$ of their original mass. Removal of cotyledonary reserves had negative effects on seedling size but no effect on root:shoot ratios.

Conclusions: Our findings indicate that the loss of cotyledonary reserves in M. coquimbensis seeds is not necessarily lethal. Moreover, we posit that tolerance to partial seed consumption is likely a key reproductive strategy, which enables recruitment in this species.
\end{abstract}

Keywords: Myrcianthes coquimbensis; Partial seed predation; Recalcitrant seed; Tolerance

\section{Background}

Seed predation is a key ecological process that can limit plant recruitment (e.g., Bricker et al. 2010) and may ultimately affect large-scale patterns of plant abundance across landscapes (Orrock et al. 2006). Seed predators commonly consume the entire seed, which results in total seed loss and reduces plant reproduction efficiency; however, partial seed consumption has also been reported for many plant species, particularly those with large seeds (e.g., Pérez et al. 2008; Mendoza and Dirzo 2009; Perea et al. 2011; Loayza et al. 2014). Although partial seed predation reduces the amount of seed reserves, the remaining fragments may still be able to

\footnotetext{
* Correspondence: aloayza@userena.cl

'Departamento de Biología, Facultad de Ciencias, Universidad de La Serena, Benavente 980, La Serena 1720170, Chile

${ }^{2}$ Instituto de Ecología y Biodiversidad, Casilla 554, La Serena, Chile Full list of author information is available at the end of the article
}

germinate and establish, especially if the embryo is left unharmed (e.g., Vallejo-Marín et al. 2006).

The ability of seeds to germinate and develop seedlings after losing part of their storage tissue has been reported for several species in different plant families, which include Myrtaceae (Texeira and Barbedo 2012), Guttiferae (Joshi et al. 2006), Fagaceae (Perea et al. 2011), and Palmae (Pérez et al. 2008), among others. In most species, germination of seed fragments can occur if the embryo remains intact (e.g., Dalling and Harms 1999; Mack 1998); however, seeds of some plants may retain their germination capabilities even if this is not the case. For example, Texeira and Barbedo (2012) demonstrated that embryonless seed fragments of five species of Eugenia were capable of germinating, which suggests that some species are capable of differentiating and forming new plants from the remaining seed tissues when the embryonic axis is damaged. 
Interestingly, all of the species for which there are reports of germination from seed fragments have recalcitrant seeds, which are characterized by being large and by having the ability to germinate early in the reserve accumulation phase of the seed (Finch-Savage and Clay 1994; Farnswroth 2000; Barbedo et al. 2013). In other words, for many recalcitrant species, the embryo is fully developed prior to shedding (but see Piña-Rodrigues and Figliolia 2005) and, consequently, seeds from green or immature fruits also have the potential to contribute to recruitment. Moreover, there is evidence for Eugenia (Myrtaceae) species that the germination behavior of fragments from mature and immature seeds does not differ, suggesting that the regenerative capacity of immature Eugenia seeds may be set before the end of the maturation process (Texeira and Barbedo 2012).

Although removal of cotyledonary reserves does not necessarily result in an inability to germinate, it can still have some effects on germination dynamics and seedling performance. For example, reduced germination percentages are usually observed with increasing damage to the seeds (e.g., Vallejo-Marín et al. 2006; Peréz et al. 2008a). Additionally, the reduction or removal of seed reserves can affect germination times but in an inconsistent manner; that is, it can either accelerate or prolong germination depending on the species (e.g., Ceballos et al. 2002; Vallejo-Marín et al. 2006). Finally, removal of cotyledon reserves may also result in decreased seedling performance (Janzen 1976; Zhang and Maun 1991; Kennedy et al. 2004), as seedling size and survival are strongly related to the amount of energy reserves in the seeds (Moles and Westoby 2004).

Myrcianthes coquimbensis (Barnéoud) Landrum et Grifo is an endangered, evergreen shrub, endemic to the Elqui Province in the southern edge of the Atacama Desert in Chile (Marticorena et al. 2001; García-Guzmán et al. 2012). It has large, subglobose fleshy drupes $(2.5 \times 3.5 \mathrm{~cm})$ that typically contain only one seed (Saldías and Velozo 2014), which is large (diameter: 0.8 to $2.5 \mathrm{~cm}$; weight: 2.6 to $11 \mathrm{~g}$ ) and recalcitrant. When ripe or green fruits fall to the ground, they are removed by rodents, which cache them and later consume both their pulp and seeds. Each year, approximately $35 \%$ of the seed crop is presumably lost to post-dispersal seed predation. Rodents, however, do not always eat seeds in their totality; often, seed damage by rodents is only partial (Loayza et al. 2014). Consequently, post-dispersal seed predation results in seed mass loss but not inevitably in seed death.

In this study, we simulated seed damage in natural conditions to test the extent to which different levels of removal of cotyledonary reserves affects germination dynamics as well as seedling performance of M. coquimbensis. Specifically, we (1) quantified the effects of cotyledon removal on seeds from mature and immature
M. coquimbensis fruits, (2) evaluated whether cotyledon fragments without the embryonic axis can produce seedlings, and (3) assessed if seed mass loss affects seedling performance. We predicted that, given that M. coquimbensis' seeds are large, their germination capability would not be affected by seed mass loss. However, we predicted that the loss of seed reserves would affect germination times and seedling performance. Finally, we hypothesized that fruit maturity at the time of seed harvest would affect germination dynamics; specifically, we predicted reduced seedling performance, as well as lower and slower germination of seeds from immature fruits.

\section{Methods}

\section{Seed source}

Seeds were obtained from mature (red) and immature (green) M. coquimbensis fruits collected in August 2013 from at least ten plants in each of three populations: Totoralillo (30 $04^{\prime} \mathrm{S}$ to $\left.71^{\circ} 22^{\prime} \mathrm{W}\right)$, Punta Teatinos $\left(29^{\circ} 49^{\prime} \mathrm{S}\right.$ to $\left.71^{\circ} 17^{\prime} \mathrm{W}\right)$, and Conchillas $\left(29^{\circ} 34^{\prime} \mathrm{S}\right.$ to $\left.71^{\circ} 19^{\prime} \mathrm{W}\right)$. Because mean seed size did not differ among these populations (Totoralillo $=2.50 \pm 1.73$ g; Punta Teatinos $=2.39 \pm 3.18$ g; Conchillas $=2.40 \pm 1.63 \mathrm{~g}$ ) and our goal was not to detect among population differences, all fruits were pooled and subsequently taken to the laboratory, where we manually removed seeds from fruits, taking care not to scratch the seed coat. We used only intact seeds for the experiments.

\section{Cutting treatments}

We selected a total of 36 immature and 36 mature $M$. coquimbensis seeds (1.2 to $7.1 \mathrm{~g})$. There was no difference in mean seed size between mature (3.24) and immature (2.86) seeds $(t=1.57 ; p=0.12)$. Each seed was randomly assigned to one of three treatments: 1 ) whole intact seeds (WIS; the control group), 2) seeds separated in half along the cotyledons (i.e., both cotyledons were intact but only one had the embryonic axis), and 3) seeds cut into four (i.e., cotyledons were separated and then each one was cut in half) (Figure 1). Before being cut, each seed was weighed individually in an analytical balance (Scaltec, SBA31). Additionally, we individually weighed all cotyledon fragments resulting from the cutting treatments before starting the experiment, keeping a record of the treatment and replicate each fragment belonged to.

\section{Emergence and morphological measurements}

In mid August 2013, all cotyledon fragments $(n=144)$ and WIS $(n=24)$ were sown in individual plastic pots in greenhouse conditions and watered regularly. We checked for emerged seedlings once a week for 6 months (August 2013 to January 2014). At the end of the experiment, we up-rooted all emerged seedlings (Figure 1) and recorded their height as a measure of seedling performance. 


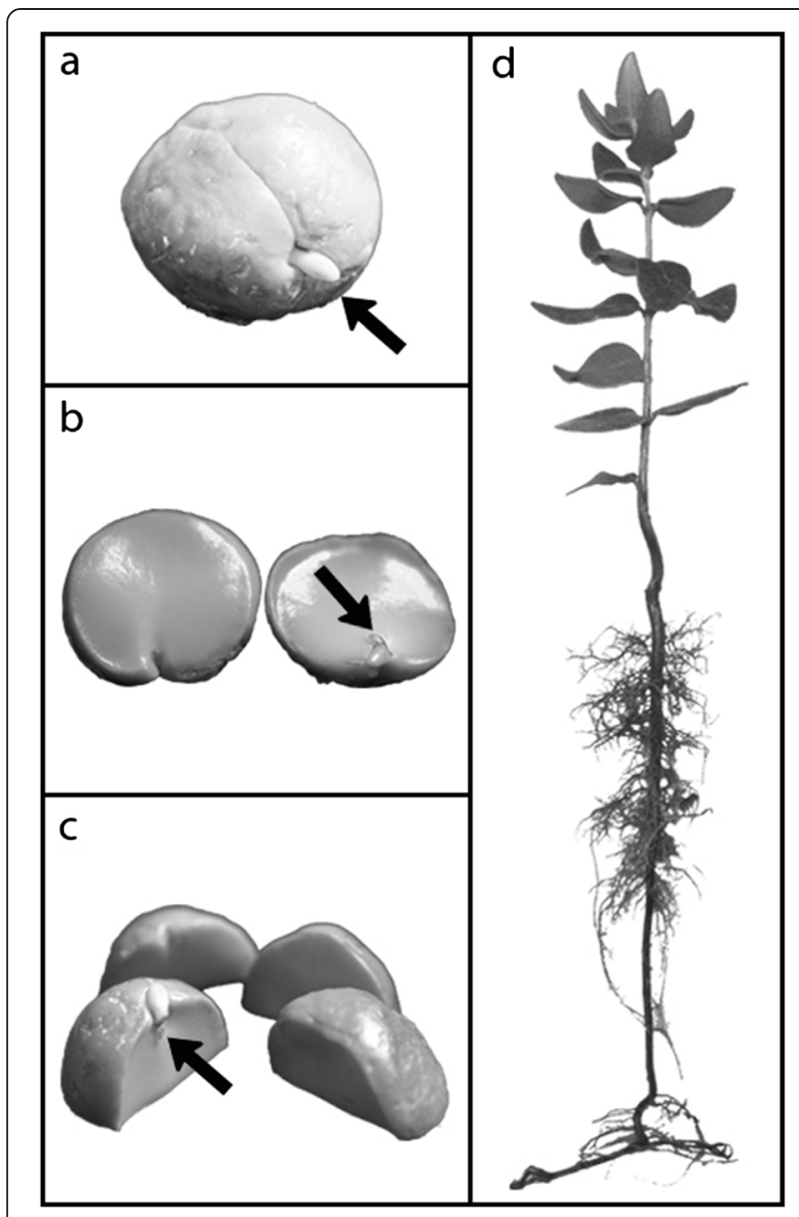

Figure 1 Fragments resulting from cutting treatments and $M$. coquimbensis seedling. (a) Mature WIS. (b) Fragments resulting from seeds cut into two; note that only one of the cotyledons (right) has the embryonic axis. (c) Fragments resulting from seeds cut into three; again, only one of the fragments (bottom left) has the embryonic axis. (d) Normal seedling development from a mature WIS. Arrows show the position of the embryonic axis.

Additionally, we oven dried stems, leafs, and roots of each seedling at $70^{\circ} \mathrm{C}$ for $48 \mathrm{~h}$ and registered their above- and belowground dry mass $(\mathrm{g})$ in an analytical balance. We used these measurements to calculate the root:shoot ratio $\left(\mathrm{g} \cdot \mathrm{g}^{-1}\right)$ for each seedling, which was considered another measure of performance. Finally, we dug up any pots that did not have emerged seedlings and checked for root development.

\section{Statistical analysis}

We examined the independent and interactive effects of cutting treatment and seed maturity on seedling emergence and root production using logistic regressions with two categorical predictors. We evaluated whether the temporal patterns of seedling emergence differed among treatments with a Cox proportional hazards model. In this analysis, the response variable is a hazard function, which describes how the probability of seedling emergence changes over time. On the other hand, the effect parameters describe how this hazard relates to seed maturity and cutting treatment, as well to the interaction between the two. We compared seedling emergence of all treatment combinations against emergence of mature WIS (baseline) because these should be the seeds most likely to produce a seedling. We assessed whether cutting treatment and seed maturity had an effect on seedling height and root:shoot ratios with general linear models. To control for seedling age, we included the number of days since emerging as a covariable in the model with seedling height. All statistical analyses were conducted using the $\mathrm{R}$ statistical environment, version 3.1.1 (R Development Core Team, 2013).

\section{Results}

Only 2 of 60 cotyledon fragments that did not have the embryo produced seedlings, therefore we considered only fragments with the embryonic axis for the analyses of seedling emergence. Overall, seedlings were able to emerge from both WIS and cotyledon fragments coming from mature and immature seeds (Figure 2). However, both cutting treatment and seed maturity affected the probability of seedling emergence (Table 1). Specifically, compared to WIS, the odds of seedling emergence were lower when seeds were cut into four or two (Figure 3). Moreover, the odds of emerging when cut into four were 0.27 times the odds of emerging when seeds were cut in half. Additionally, mature seeds had three times the odds of emerging compared to immature seeds. Consequently, although $M$. coquimbensis seeds retain their ability to emerge after losing portions of their storage tissue, the probability of emergence is negatively related to both the amount of cotyledon reserves lost and seed maturity.

Cutting treatment and seed maturity also affected the temporal pattern of seedling emergence $\left(\chi^{2}=13.85, \mathrm{df}=5\right.$, $p=0.02$; Table 2). Compared to WIS, seedling emergence was ca. $73 \%$ slower (1- $\beta$ exp) for seeds cut in four but did not differ with seeds cut in two. Similarly, immature seeds emerged slower than mature ones (Table 2).

Approximately $76 \%$ of all cotyledon fragments (including those without the embryonic axis) produced roots. The probability of root production was affected by cutting treatment only (Table 1). The odds of fragments from seeds cut into two producing roots were 0.07 and 0.5 the odds of WIS and fragments from seeds cut into four producing roots, respectively. There was no difference in the odds of producing roots between fragments from seeds cut in four and WIS.

Controlling for time since emergence, only cutting treatment affected seedling height (Table 3); specifically, seedlings from WIS and from fragments of seeds cut into two were taller than those from fragments of seeds cut into four (Figure 4). Finally, root:shoot ratios of 


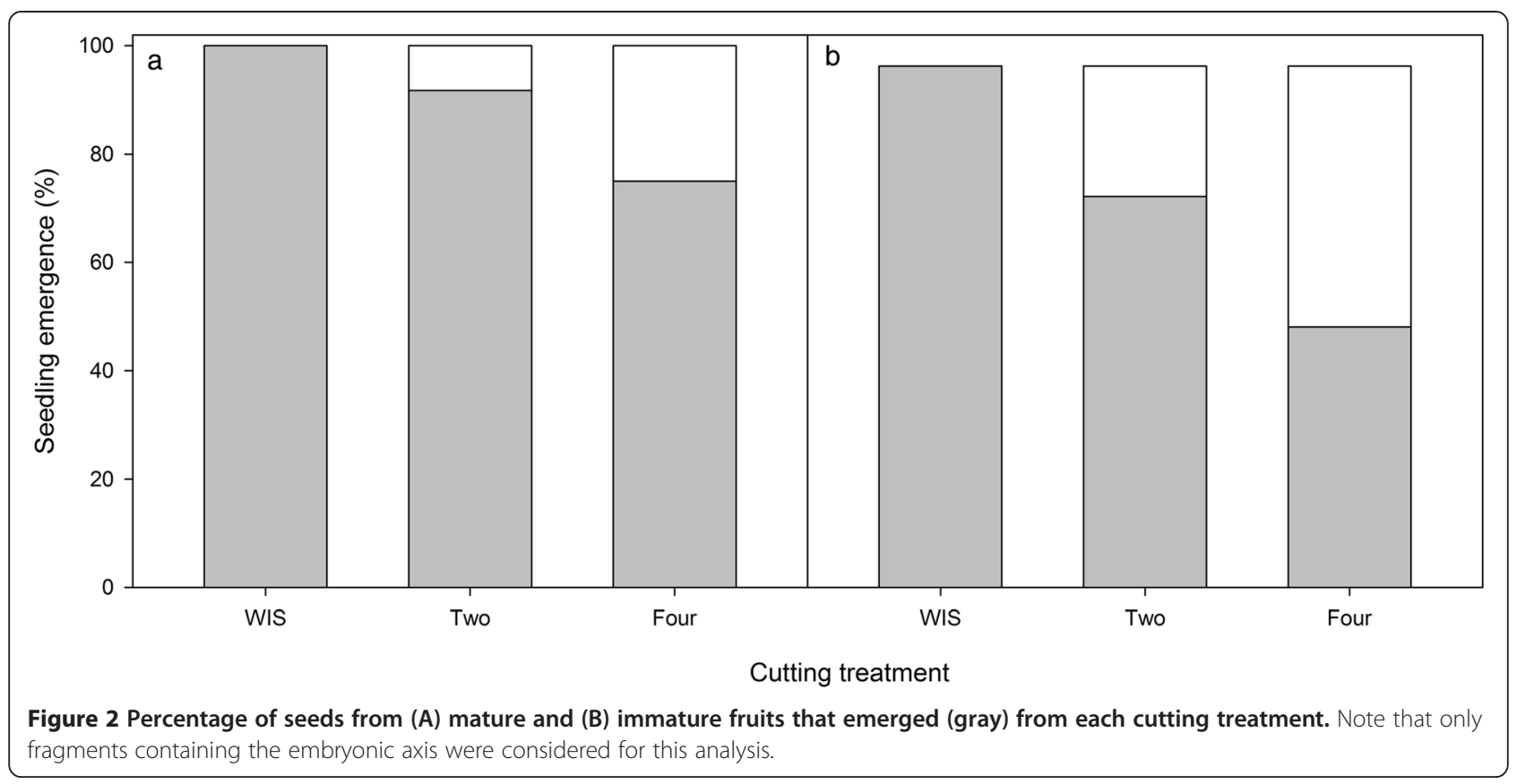

emerged seedlings did not differ among cutting treatments, seed maturity, or their interaction (Table 3).

\section{Discussion}

M. coquimbensis is another example of a species that is remarkably tolerant to seed damage. Although this regenerative ability has been documented in a previous study (Loayza et al. 2014), here we provide new empirical evidence revealing that: 1) cotyledon fragments can seldom produce a seedling without an embryonic axis; 2) fruit maturity when seeds are harvested affects the probability of emergence; 3) fragments can produce roots even without embryos; and 4) removal of the storage tissue affects seedling growth but not the relationship between above- and belowground biomass.

As reported for other large-seeded species (e.g., Dalling et al. 1997; Dalling and Harms 1999; Perez et al. 2008; Menzoza and Dirzo, 2009; Texeira and Barbedo 2012), the

Table 1 Logistic regression model of the effects of cutting treatment and seed maturity

\begin{tabular}{llll}
\hline & df & Deviance & Probability $\left(x^{2}\right)$ \\
\hline Seedling emergence & & & \\
Cutting treatment (C) & 2 & 13.93 & $<0.001$ \\
Seed maturity (M) & 1 & 4.37 & 0.04 \\
C*M $^{*}$ & 2 & 0.35 & 0.84 \\
Root development & & & \\
Cutting treatment (C) & 2 & 10.73 & 0.005 \\
Seed maturity (M) & 1 & 0.19 & 0.66 \\
C $^{*}$ M & 2 & 1.63 & 0.44 \\
\hline
\end{tabular}

On M. coquimbensis seedling emergence and root development. development of the initial seedling of $M$. coquimbensis required only a small fraction of the total storage tissue, indicating that these seeds have more cotyledonary reserves than what is strictly needed for germination and seedling expansion. There are at least two, non-exclusive, explanations that can account for the production of oversize cotyledons. First, large seed size may constitute a plant tolerance trait, i.e., an antipredation mechanism that allows seeds to tolerate damage from seed predators (Vallejo-Marín et al. 2006; Pérez et al. 2008; Mendoza and Dirzo 2009) and/or seedling herbivory (Dalling et al. 1997; Green and Juniper 2004). In the first scenario, an oversized package of reserves should enable seeds to tolerate damage from predators (i.e., seed mass loss) and retain their ability to germinate, whereas in the second, the 'extra' storage tissue is necessary for the resprouting of new seedlings after severe aboveground shoot clipping. Therefore, in both cases, reserves in the cotyledons may act as a 'risk hedge' (Hoshizaki et al. 1997) against physical damage of the seeds and/or herbivory of the initial shoots. Alternatively, large seed size is also favored in recalcitrant species because it is considered a proxy of desiccation tolerance (Dickie and Pritchard 2002; Daws et al. 2005). In this sense, larger seeds take longer to dry than smaller ones (Daws et al. 2006a, b) and are thus able to survive longer after initial dispersal. In the case of $M$. coquimbensis, tolerance to both desiccation and seed predation may account for the large amount of cotyledonary reserves. Tolerance to seed predation is particularly important for this species, because it has no present day dispersers and relies solely on rodents - its seed predators - to transport seeds to suitable sites for establishment (Loayza et al. 2014). Consequently, $M$. coquimbensis is subject to intense levels 


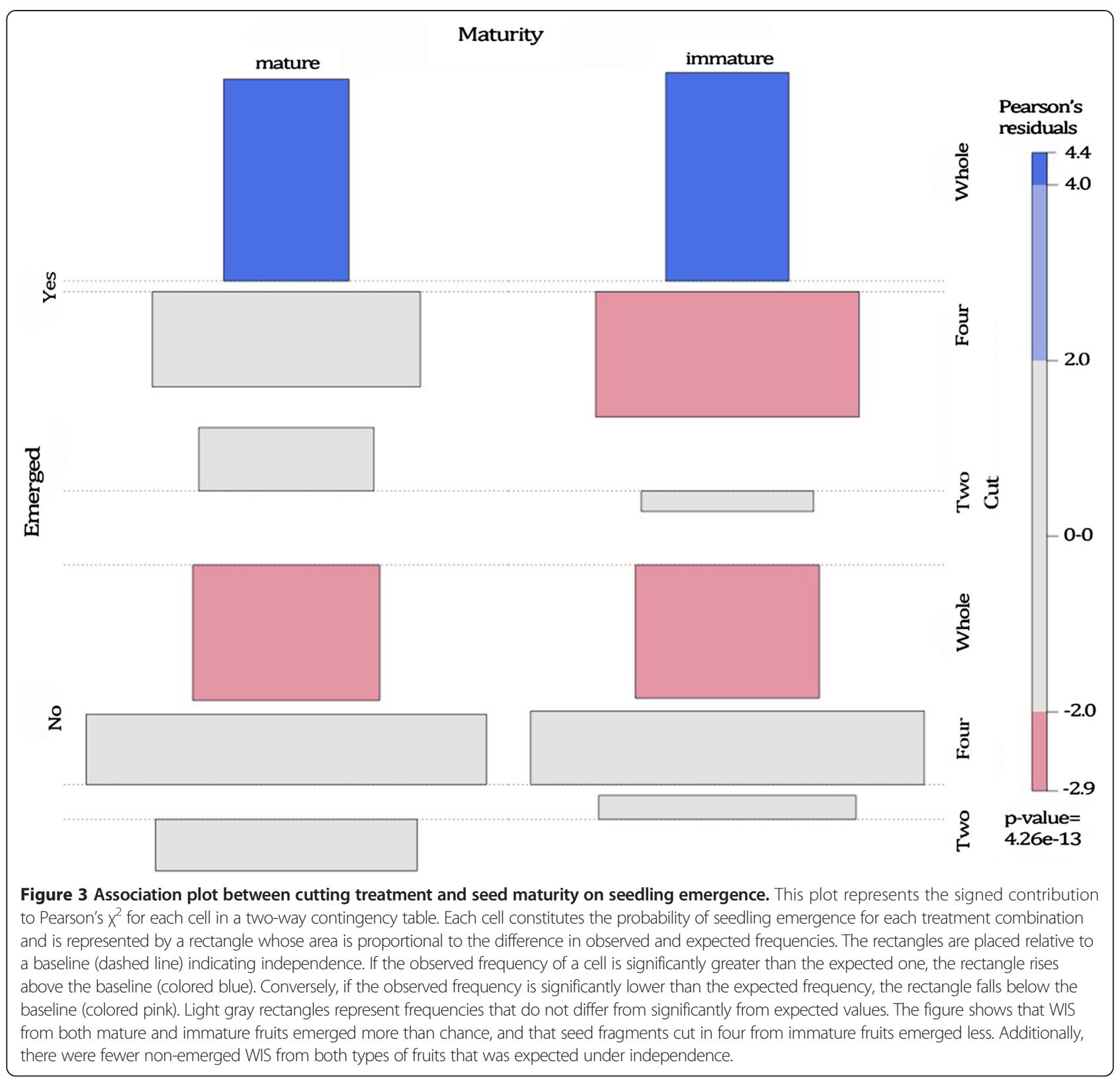

Table 2 Cox proportional hazards regressions of seedling emergence

\begin{tabular}{lllll}
\hline Factors & $\boldsymbol{\beta}$ & $\boldsymbol{\beta} \exp$ & $\mathrm{SE}_{(\boldsymbol{\beta})}$ & $\boldsymbol{p}$ \\
\hline Seeds cut in four & -1.299 & 0.273 & 0.460 & 0.005 \\
Seeds cut in two & -0.554 & 0.574 & 0.437 & 0.205 \\
Immature seeds & -1.018 & 0.361 & 0.440 & 0.021 \\
Seeds cut in four * immature & 0.889 & 2.431 & 0.706 & 0.208 \\
Seeds cut in two * immature & 0.036 & 0.964 & 0.668 & 0.956
\end{tabular}

Note that the baseline for all treatments was seedling emergence from mature intact seeds. of post-dispersal seed predation, and investing in producing large seeds may be a strategy to partially escape mortality and increase plant reproduction efficiency. On the other hand, tolerance to desiccation may be equally critical for this species because it grows in an extremely arid environment where mean annual rainfall for the past 10 years averaged $75 \mathrm{~mm}$. This strongly contrasts to the environments where the majority of recalcitrant species are found, which are predominantly humid and wet (Fenner 2000; Farnsworth 2000; Berjak and Pammenter 2008).

In spite of retaining their ability to germinate, seeds that lost ca. $75 \%$ their seed mass had lower odds of emergence and slower emergence times than WIS. Cutting seeds into four may have reduced the seed mass 
Table 3 Analysis of variance for the effect of cutting treatment and seed maturity

\begin{tabular}{lllc}
\hline & df & $\boldsymbol{F}$ & $\boldsymbol{p}$ \\
\hline Seedling height & & & \\
Cutting treatment (C) & 2 & 8.25 & $<0.001$ \\
Seed maturity (M) & 1 & 3.17 & 0.08 \\
Time since emergence & 1 & 1.77 & 0.19 \\
C*M $^{*}$ & 2 & 0.74 & 0.48 \\
Root:shoot ratios & & & \\
Cutting treatment (C) & 2 & 1.68 & 0.21 \\
Seed maturity (M) & 1 & 0.25 & 0.62 \\
C*M & 2 & 0.46 & 0.63 \\
\hline
\end{tabular}

On seedling height (including days since emergence as a covariable) and root: shoot ratios of emerged seedlings.

content so much that it limited the availability of reserves for seedling emergence. Germination success of partially damaged seeds is frequently, though not always, reduced compared to the germination of intact seeds (e.g., Janzen 1976; Koptur 1998; Branco et al. 2002; Vallejo-Marín et al. 2006). In some cases, there can be total germination failure with only a small percentage of seed mass loss (Vallejo-Marín et al. 2006), whereas in others germination success is only reduced after large percentages of seed mass have been lost (e.g., Dalling et al. 1997; Mendoza and Dirzo 2009). Results from this study, indicate that $M$. coquimbensis falls within the latter and again reveals its great capacity to tolerate seed damage.

Seedlings emerged from both seed fragments and WIS of both mature and immature fruits; nonetheless, fruit maturity significantly affected probability of emergence and the temporal pattern of seedling emergence. Maturity has been shown to have both positive and negative effects on germination. For example, Sanchez and collaborators (1993) found that seeds of Capsicum annum (orthodox seeds) collected from unripe fruits failed to germinate, whereas seeds collected from ripe fruits had high levels of germination. Conversely, immature seeds of Juniperus oxycedrus (recalcitrant species) had higher germination percentages than mature ones (Juan et al. 2003). A lower emergence probability of seeds from immature $M$. coquimbensis fruits may be explained in part because immature recalcitrant seeds are more desiccation sensitive than mature ones (Berjak and Pammenter 2010), and thus a higher proportion of these seeds may have died before emerging. Additionally, it is possible - though less likely - that immature seeds may not have accumulated enough seed reserves for germination (Barbedo et al. 2013).

The majority of cotyledon fragments, with or without an embryo, were able to develop roots. Similar results were obtained by Texeira and Babedo (2012) with recalcitrant seeds of five species of Eugenia, a closely related genus of Myrcianthes (Lucas et al. 2007). Moreover, these authors showed that cotyledon fragments retained their ability to produce roots, even when seeds were cut after the germination process had initiated (i.e., after the original seed had produced the primary root). This suggests that even small cotyledon fragments have sufficient reserves after germination to produce roots. In this sense, Kennedy and collaborators (2004) found that seed reserves have a significant impact on early plant development, and

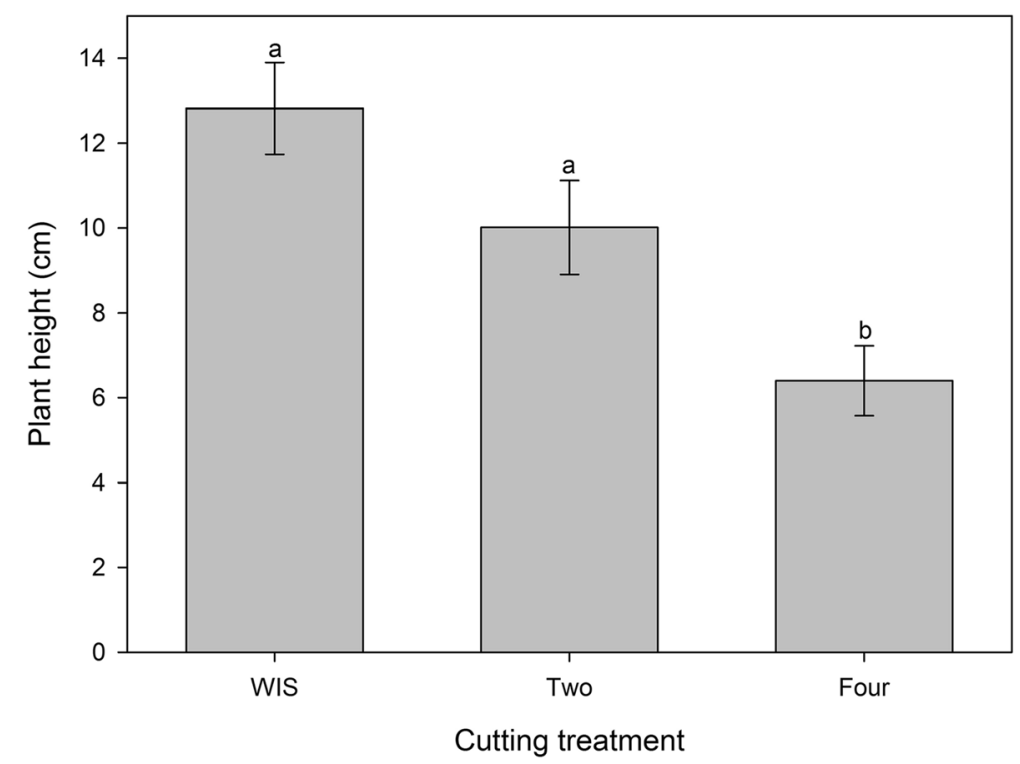

Figure 4 Mean height of seedlings emerging from seeds exposed to the different cutting treatments. Differences in height were controlled for seedling age (days since emergence). Lowercase letters indicate significant statistical differences among cutting treatments $(a, a, b)(p<0.05)$. Error bars represent \pm 1 standard error. 
that a significant amount of the carbon in seeds moves directly to the roots. Whether all fragments with roots will later be able to produce seedlings is unknown. As mentioned previously, only two cotyledon fragments without the embryonic axis were able to produce seedlings, which strongly suggests that, even if they are able to produce roots, embryonless fragments will unlikely generate seedlings, particularly in natural conditions.

Cutting treatment affected seedling height; controlling for time since emergence, seedlings that developed from seeds that had lost approximately $75 \%$ of their mass were consistently smaller than those from the other two treatments. If large seed size in $M$. coquimbensis is partly explained by the 'reserve effect' hypothesis (Westoby 1996; Leishman et al. 2000) - which states that larger seeds retain a greater proportion of their seed reserves after germination that can be mobilized for seedling growth, maintenance, and repair - then it follows that after germinating, both WIS and seeds that lost only half of their storage tissue, had more seed reserves to allocate to seedling growth than the small cotyledon fragments and would ultimately produce larger seedlings (Kennedy et al. 2004). Finally, root:shoot ratios of emerged seedlings did not differ among cutting treatments, seed maturity, or their interaction, which suggests that although the amount of cotyledon reserves affects plant growth, it does not affect resource allocation to above and belowground organs.

\section{Conclusions}

In conclusion, our findings indicate that the loss of cotyledonary reserves in $M$. coquimbensis seeds is not necessarily lethal. Seed mass loss, however, affected the temporality of emergence as well as seedling size, which may have critical consequences for the regeneration of this species. Tolerance to partial seed consumption is likely a key reproductive strategy, which enables recruitment in this species. We suggest that future studies should focus on understanding which factors (e.g., resource availability, variation in intraspecific seed size) influence whether rodents eat seeds whole or partially, as this will enable to further understand the consequences and ecology of partial seed predation.

\section{Abbreviations}

WIS: whole intact seeds.

\section{Competing interests}

The authors declare that they have no competing interests.

\section{Authors' contributions}

APL performed statistical analyses and wrote the first draft of the manuscript. PRG carried out the experimental procedures. PGG and DEC collected the data, elaborated figures, and contributed substantially to the discussion. FAS contributed substantially to revisions. All authors read and approved the final manuscript.

\section{Acknowledgements}

This research was supported by the Chilean Millennium Initiative (ICMP02-051-F) and CONICYT (PFB-23); a FONDECYT postdoctoral grant (APL, grant number 3120123); and CONYCIT doctoral fellowships (D.E.C., grant number 21140050), (P.G.G., grant number 21120854).

\section{Author details}

'Departamento de Biología, Facultad de Ciencias, Universidad de La Serena, Benavente 980, La Serena 1720170, Chile. ${ }^{2}$ Instituto de Ecología y Biodiversidad, Casilla 554, La Serena, Chile. ${ }^{3}$ Programa de Doctorado en Biología y Ecología Aplicada, Universidad de La Serena, Raúl Bitrán 1305, La Serena, Chile. ${ }^{4}$ Centro de Estudios Avanzados en Zonas Áridas (CEAZA), Raúl Bitrán 1305, La Serena, Chile.

Received: 5 November 2014 Accepted: 24 March 2015

Published online: 21 April 2015

\section{References}

Barbedo CJ, Centeno da Cruz D, Leone Figueiredo Ribeiro RC (2013) Do recalcitrant seeds really exist? Hoehnea 40:583-593

Berjak P, Pammenter NW (2008) From Avicennia to Zizania: seed recalcitrance in perspective. Ann Bot 101:213-228

Branco M, Branco C, Merouani H, Almeida MH (2002) Germination success, survival and seedling vigor of Quercus suber acorns in relation to insect damage. Forest Ecol Man 166:159-164

Bricker M, Pearson D, Maron JL (2010) Small mammal seed predation limits the recruitment and abundance of two perennial grassland forbs. Ecology 91:85-92

Ceballos L, Andary C, Delescluse M, Gibernau M, Mckey D, Hossaert-Mckey M (2002) Effects of sublethal attack by a sucking insect, Hyalymenus tarsatus, on Sesbania drumondii seeds: impact on some seed traits related to fitness. Ecoscience 9:28-36

R Core Team (2013). R: A language and environment for statistical computing. $R$ Foundation for Statistical Computing, Vienna, Austria. URL http://www.R-project.org/.

Dalling JW, Harms KE (1999) Damage tolerance and cotyledonary resource use in the tropical tree Gustavia superba. Oikos 85:257-264

Dalling JW, Harms KE, Aizprúa R (1997) Seed damage tolerance and seedling resprouting ability of Prioria copaifera in Panamá. J Trop Ecol 13:481-490

Daws MI, Garwood NC, Pritchard HW (2005) Traits of recalcitrant seeds in a semi-deciduous tropical forest in Panama: some ecological implications. Funct Ecol 19:874-885

Daws MI, Garwood NC, Pritchard HW (2006a) Prediction of desiccation sensitivity in seeds of woody species: a probabilistic model based on two seed traits and 104 species. Ann Bot 97:667-674

Daws MI, Cleland H, Chmielarz P, Gorian F, Leprince O, Mullins CE, Thanos CA, Vandvik V, Pritchard HW (2006b) Variable desiccation tolerance in Acer pseudoplatanus seeds in relation to developmental conditions: a case of phenotypic recalcitrance? Funct Plant Biol 33:59-66

Dickie JB, Pritchard HW (2002) Systematic and evolutionary aspects of desiccation tolerance in seeds. In: Black M, Pritchard HW (eds) Desiccation and survival in plants: drying without dying. CAB International, Wallingford, UK, pp 239-259

Farnsworth E (2000) The ecology and physiology of viviparous and recalcitrant seeds. Ann Rev Ecol Syst 31:107-138

Fenner M (ed) (2000) Seeds: the ecology of regeneration in plant communities, 2nd edn. Oxford, CAB International

Finch-Savage WE, Clay HA (1994) Water relations of germination in the recalcitrant seeds of Quercus robur L. Seed Sci Res 4:315-322

García-Guzmán P, Loayza AP, Carvajal DE, Letelier L, Squeo FA (2012) Ecology, distribution and conservation status of Myrcianthes coquimbensis: A globally endangered endemic shrub of the Chilean Coastal Desert. Plant Ecol Divers 5:197-204

Green PT, Juniper PA (2004) Seed mass, seedling herbivory and the reserve effect in tropical rainforest seedlings. Funct Ecol 18:539-547

Hoshizaki K, Suzuki W, Sasaki S (1997) Impacts of secondary seed dispersal and herbivory on seedling survival in Aesculus turbinata. J Veg Sci 8:735-742

Janzen DH (1976) Reduction of Mucuna andreana (Leguminosae) seedling fitness by artificial seed damage. Ecology 57:826-828 
Joshi G, Arun Kumar AN, Gowda B, Srinivasa YB (2006) Production of supernumerary plants from seed fragments in Garcinia gummi-gutta: evolutionary implications of mammalian frugivory. Curr Sci 91:372-376

Juan R, Pastor J, Fernández I, Diosdado JC (2003) Relationships between mature cone traits and seed viability in Juniperus oxycedrus L. subsp. macrocarpa (Sm.) Ball (Cupressaceae). Acta Biol Cracov Bot 45:69-78

Kennedy PG, Hausmann NJ, Wenk EH, Dawson TE (2004) The importance of seed reserves for seedling performance: an integrated approach using morphological, physiological, and stable isotope techniques. Oecologia 141:547-554

Koptur S (1998) Effects of seed damage on germination in the common vetch (Vicia sativa I.). Am Mid Nat 140:393-396

Leishman MR, Wright IJ, Moles AT, Westoby M (2000) The evolutionary ecology of seed size. In: Fenner M (ed) Seeds: ecology of regeneration in plant communities. CAB International, Wallingford, UK, pp 31-57

Loayza AP, Carvajal DE, García-Guzmán P, Gutierrez JR, Squeo FA (2014) Seed predation by rodents results in directed dispersal of viable seed fragments of an endangered desert shrub. Ecosphere 5:43

Lucas EJ, Harris SA, Mazine FF, Belsham SR, Nic Lughadha EM, Telford A, Gasson PE, Chase MW (2007) Suprageneric phylogenetics of Myrteae, the generically richest tribe in Myrtaceae (Myrtales). Taxon 56:1105-1128

Mack AL (1998) An advantage of large seed size: tolerating rather than succumbing to seed predators. Biotropica 30:604-608

Marticorena C, Squeo FA, Arancio G, Muñoz M (2001) Catálogo de la flora vascular de la IV Región de Coquimbo. In: Squeo FA, Arancio G, Gutiérrez JR (eds) Libro Rojo de la Flora Nativa de la Región de Coquimbo y de los Sitios Prioritarios para su Conservación. Ediciones de la Universidad de La Serena, La Serena

Menzoza E, Dirzo R (2009) Seed tolerance to predation: evidence from the toxic seeds of the buckeye tree (Aesculus californica; Sapindaceae). Am J Bot 96:1255-1261

Moles AT, Westoby M (2004) Seedling survival and seed size: a synthesis of the literature. J Ecol 92:372-383

Orrock JL, Levey DJ, Danielson BJ, Damschen El (2006) Seed predation, not seed dispersal, explains the landscape-level abundance of an early-successional plant. J Ecol 94:838-845

Perea R, San Miguel A, Gil L (2011) Leftovers in seed dispersal: ecological implications of partial seed consumption for oak regeneration. J Ecol 99:194-201

Pérez HE, Shiels AB, Zaleski HM, Drake DR (2008) Germination after simulated rat damage in seeds of two endemic Hawaiian palm species. J Trop Ecol 24:555-558

Pina-Rodrigues FCM, Figliolia MB (2005) Embryo immaturity associated with delayed germination in recalcitrant seeds of Virola surinamensis (Rol.) Warb. (Myristicaceae). Seed Sci Technol 33:375-386

Saldías G, Velozo J (2014) Estudio de la propagación de Myrcianthes coquimbensis (Barnéoud) Landrum et Grifo por semillas y esquejes. Gayana Bot 71:17-23

Sanchez VM, Sundstrom GN, McClure GN, Lang NS (1993) Fruit maturity, storage and postharvest maturation treatments affect Bell pepper (Capsicum annum L.) seed quality. Sci Hortic 54:191-201

Texeira CC, Barbedo CJ (2012) The development of seedlings from fragments of monoembryonic seeds as an important survival strategy for Eugenia (Myrtaceae) tree species. Trees 26:1069-1077

Vallejo-Marín M, Domínguez CA, Dirzo R (2006) Simulated seed predation reveals a variety of germination responses of neotropical rain forest species. Am $J$ Bot 93:369-376

Westoby M, Leishman MR, Lord JM (1996) Comparative ecology of seed size and seed dispersal. Phils T Roy Soc B 351:1309-1318

Zhang J, Maun MA (1991) Effects of partial removal of seed reserves on some aspects of seedling ecology of seven dune species. Can J Ecol 69:1457-1462

\section{Submit your manuscript to a SpringerOpen ${ }^{\circ}$ journal and benefit from:}

- Convenient online submission

- Rigorous peer review

- Immediate publication on acceptance

- Open access: articles freely available online

- High visibility within the field

- Retaining the copyright to your article

Submit your next manuscript at $>$ springeropen.com 